\title{
KARL AUGUST HERMANNI HIINA-SOOME-EESTI KEELEVÕRDLUS NING KEHTIVAD JA KEHTETUD ETÜMOLOOGIAD PARANDUSTEGA
}

\author{
Jingyi Gao \\ Beijing International Studies University
}

\begin{abstract}
Kokkuvõte. Selles töös on üle vaadatud Karl August Hermanni 1895. aastal ilmunud artikkel, milles ta võrdles mandariinihiina keelt uurali keeltega, eriti eesti ja soome keelega, ning järeldas, et need keeled on omavahel suguluses. Hermanni toodud tõendid fonoloogia, morfoloogia ja süntaksi alal on mitmesugused. Hermanni leitud mõistete sarnasused on originaalsed. Selle töö autori hinnangul on Hermanni töös välja toodud kaheksast etümoloogilisest võrdlusest viis kehtivad, üks kahtlane, kaks kehtetud. Autor on täiendanud kehtivaid võrdlusi ja parandanud kehtetuid võrdlusi. Nende etümoloogiliste võrdluste tõestamiseks on välja toonud veel 12 etümoloogilist võrdlust, mille loovad kas sõnaalguline või riimivastavus. Tulemusena on esitatud kokku 19 hiinauurali etümoloogiat.
\end{abstract}

Märksõnad: keelesugulus, etümoloogia, hiina keel, hiina keelkond, eesti keel, soome keel, hiina-uurali, uurali, soome-ugri keeled

DOI: https://doi.org/10.12697/jeful.2019.10.2.03

\section{Sissejuhatus}

Viimasel kahel aastakümnel on ainsana hiina keeleteadlane Jingyi Gao võrrelnud eesti keelt ja teisi uurali keeli hiina keelkonnaga. Kuigi hiina autor on avaldanud mitu eri tasemel uurimistööd (vt viimased publikatsioonid koos uurimislooga: Gao 2014a, 2015a, 2015b, 2019), millele nii hiina teadlased (nt Féng 2008, Lǐ ja Lǐ 2011, Wáng 2012: 3, Táng jt 2016) kui ka mitu Eesti teadlast (nt Künnap 2009, 2010, Sutrop 2010, Läänemets 2010, Kaplinski 2014) on andnud head tagasisidet, enamik Eesti teadlasi ikka veel vaikib sel teemal. Selgub aga, et enam kui 100 aastat tagasi avaldas eesti keeleteadlane Karl August Hermann artikli „Ueber die Verwandtschaft des Chinesischen mit den ugrischen Sprachen und insbesondere mit dem Finnisch-Estnischen“ [,Hiina keele sugulusest ugri ${ }^{1}$ keelte ja eriti soome-eesti keelega"] ja jõudis järeldusele, et need keeled on omavahel suguluses (Hermann 1895: 180).

1 Tänapäeva uurali tähenduses (autori märkus). 
Hermann (1895: 167) kirjutas oma artikli alguses: „Es ist in jüngster Zeit viel darüber gesprochen worden, ob die große Kultursprache Ostasiens, das Chinesische, zu den ugrischen Sprachen in einem verwandschaftlichen Verhältnisse stehe oder nicht" [,Kõige viimasel ajal on palju selle üle räägitud, kas Ida-Aasia suur kultuurkeel, hiina keel, on sugulussuhtes ugri keeltega või mitte“2]. „Von mancher Seite ist eine solche Verwandtschaft einfach in Abrede gestellt worden, Andere dagegen haben sie als feststehende Tatsache angeführt. Zu den letzteren gehören gerade die besten Kenner dieser Sprachen, wie W. Schott. Mag Müller, Friedrich Müller, H. und G. von der Gabelentz“ [,„Nii mõneltki poolt on sellist sugulust eitatud, seevastu teised on selle kui kindla tõsiasja esile toonud. Viimaste hulka kuuluvad nende keelte parimad tundjad nagu W. Schott, Max Müller, H. ja G. von Gabelentz"] (Hermann 1895: 167-168).

Hermann (1895: 169) möönis siis: „Es sei aber hier gesagt, daß zur wissenschaftlichen Begründung dieses Verwandtschaftsverhältnisses zwischen diesen Sprachen sehr wenig thatsächliches Material erbracht worden ist“ [",Olgu aga siin öeldud, et nende keelte vaheliste sugulussuhete teaduslikuks põhjendamiseks on toodud väga vähe faktilist materjali“"]. „Die Aufgabe ist auch zu groß, als daß sie sich durch ein kurzes Studium bei vorübergehender Forschung lösen ließe“ [,Ülesanne on selleks liiga suur, et see laseks end lahendada põgusa materjali kogumise põhjal lühikeses uurimistöös“]. „Dennoch kann den Männern der Wissenschaft, welche sich hierüber eine Ansicht gebildet haben, das Recht nicht abgesprochen werden, dieser ihrer Ansicht Ausdruck zu geben, zumal kaum zu erwarten ist, daß irgendwelcher Staat oder irgendwelches Institut die Mittel dazu hergeben wird, damit Gelehrte an der Lösung dieser Riesenaufgabe arbeiten könnten“ [,„Siiski ei või teaduse meestelt, kes on selle kohta siin oma arvamuse kujundanud, võtta õigust oma arvamust väljendada, seda enam, et on vaevalt oodata, et mõni riik või mõni instituut annaks selleks vahendeid, millega õpetlased selle hiigelülesande lahendamiseks saaksid töötada"].

Hermann esitas seejärel tõendeid keelematerjalist. Fonoloogia alal esitas Hermann (1895: 70) tõendiks eelkõige selle, et hiina keele sõnatüved on ühesilbilised; uurali keelte sõnatüved pidid olema samuti

2 Siin ja edaspidi Hermanni (1895) artikli tsitaadid Urmas Sutropi tõlkes (Hermann 2019 siinses väljaandes). 
ühesilbilised, kuna eesti keeles teise silbi vokaal on muutuv, seega võis see olla sekundaarne. See Hermanni väide ei ole tänapäeva keeleteaduses kehtiv. Tüvevokaal /a/ või /e/ on algupärane. Uurali tüvisõnad olid algselt kahesilbilised. Ma oletan, et see Hermanni kehtetu väide oli peamine põhjus, miks tema kolleegid ja hilisemad eesti keeleteadlased ei jätkanud tema välja pakutud hiina keele uurimissuunda. See siiski ei ole takistus. Vanimad hiina keele tüvisõnad pidid olema samuti kahesilbilised. Praegune ühesilbilisus on keele hilisema arengu, lõpukao ja laadivahelduse tulemus (Gāo 2013, 2014b, Gao 2015a). Hermann (1895: 174) lisas veel: „Bezüglich der Anlauts hat das Chinesische gleichfalls Ähnlichkeit mit den ugrischen Sprachen. Wie bei diesen, ist auch der Anlaut der chinesischen Sprache im Ganzen einfach“ [,Sõna algushäälikute suhtes on hiina keelel samuti sarnasus ugri keeltega. Nagu nendelgi, on hiina keele algushäälik üldiselt lihtne"]. See väide on kehtiv. Nii nagu soome keeles, on ka hiina keeles sõnaalguline kaashälilikuühend võimatu. Hermann (1895: 174) arvas veel: [mandariini] hiina keeles lõpeb silp ainult vokaali või nasaaliga ( $-n$ või $-n g)$. Hiina keeles lõpeb silp konsonandiga $-p$, $-t$, või $-k$ ainult mõnes murdes. Soome keeles lõpeb silp ainult vokaali või nasaaliga $-n$. Soome keeles lõpeb silp konsonandiga - $p$, $-t$, või $-k$ samuti ainult mõnes murdes. See Hermanni väide on kehtiv. Eriti kiiduväärt on see, et ta oli teadlik hiina murretest.

Morfoloogia alal esitas Hermann tõendiks selle, et hiina, uurali ja altai keeltes ei ole sõnadel sugu. See väide on kehtiv. Kuna see tunnus on aga laialt levinud, ei tõesta see veel midagi väga erilist.

Süntaksi alal esitas Hermann tõendiks selle, et hiina ja uurali keeltes on täiend põhisõna ees, mitte nagu paljudes indoeuroopa keeltes, kus täiend on põhisõna järel. See väide on kehtiv. Kuna see tunnus on väga suure tõenäolisuse tulem, ei tõesta see samuti veel midagi väga erilist. Hermann möönis ise ka, et see on tema artiklis kõige nõrgem väide.

Hermann (1895: 176-177) esitas algupärased tõendid mõistete sarnasusest. Ta avastas, et hiina ja eesti keele väljendites on sarnased mõisted. Eesti keeles on Tallinna mees, Tartu mees, Pärnu mees; hiina keeles on Peking jin [Běi-jīng rén 'Pekingi inimene'] , Nan-king jin [Nán-jīng rén 'Nanjingi inimene'], Kuang-tung jin [Guăng-dōng rén 'Guangdongi

3 Esimesena esitatud sõnakuju on Hermanni artiklist. Nurksulgudes olev sõnakuju on kehtiva ortograafia järgi. 
inimene']. Eesti keele on mõni hää sada inimesi; hiina keeles on hao ki pe ko jin [hăo jǔ băi rén 'hea mitu sada inimest']. Eesti keeles on taevaalune; hiina keeles tien-hia [tiān-xià 'taeva all'], mis tähendabki maailma. Eesti keeles on putukate tõug; hiina keeles tschung-lui [chóng-lèi 'puutuka-laad'] tähendabki putukaid. Hermann esitas veel kaks hiina keele näidet you always look at yourself ${ }^{4}$ koos eesti keele vastega, mis paraku ei ole hiina keeles õiged. Ma arvan, et mõistete sarnasused on huvitavad, aga laienevad ilmselt kergesti ka teistele keeltele.

Etümoloogia alal kirjutas Hermann, et ühised tüvisõnad on kõige olulisemad tõendid. Hermann esitab artiklis kokku kaheksa tüvisõnavõrdlust. Ta võrdleb peamiselt ainult mandariinihiina (edaspidi: mandariini), soome ja eesti tüvisõnu. Ta ei esitanud üldist hiina etümoloogiat ega kaasanud hiina keelkonna etümoloogilisi vasteid. Lisan järgnevas analüüsis hiina etümoloogia koos hiina keelkonna ja teiste uurali keelte etümoloogiliste vastetega. Teiste hiina keelte etümoloogilised vasted on kogutud hiina filoloogia traditsioonist: hiina keelkonna keeled või murded kasutavad ühist ajaloolist kirjasüsteemi (hanzi), hiina filoloogid saavad keele- või murdesõna (sõna kõnes või foneetilises kirjas) etümoloogia tuvastada sõna tähistava hanzi kirjamärgi järgi, siiski ka kirjamärgi järgi öelda selle keele- või murdesõnad vähemalt riigikeeles ja oma murdes. Need ühele kirjamärgile kuuluvad keele- või murdesõnad ongi etümoloogilised vasted. Kui hiina kirjamärk on antud, on selle hiina keelkonna etümoloogilised vasted teoreetiliselt kaasatud. Teos, kus etümoloogilised vasted on tabelitena välja kirjutatud, on näiteks 2003-FYZH, milles on 3000 etümoloogiat (kirjamärki) ja nende etümoloogilised vasted (kirjutatud IPA-s) 20 hiina keelekujus ehk murdes. Oma piiratud mahu tõttu on see aga pigem näidisteos kui esmane uurimisallikas. Teiste uurali keelte kui eesti ja soome keele etümoloogilised vasted on võetud etümoloogilistest sõnaraamatutest: 1988-UEW, 2001-SSA ja 2012-EES. Lisan järgnevas analüüsis ka kehtivale etümoloogiale riimivastavused õiendiks. Riimivastavus tähendab, et sama lõppriimi kandvatel tüvisõnadel on võrreldud keeltes korduvalt vasted, nt kui eesti tüvisõna sündi- vastab mandariini tüvisõnale shēng 'sündima', siis eesti tüvisõna künd(a)- vastab mandariini tüvisõnale gēng 'kündma' (Gao 2014a, 2019).

4 hao suan jin; sien-scheng-ti' sie liao schu-king. 


\section{Etümoloogiad ja arutlused}

\section{H1. mandariini kong 'auk' soome konkelo 'kõverus, kõverik' eesti kong - kahtlane etümoloogia}

Hermann leidis selle võrdluse Wilhelm Schotti tööst, mille viidet ta ei ole aga andnud. Selle hiina etümoloogia on tegelikult【孔】: mandariini kǒng 'auk'; kantoni hung2 'auk'; minnani khóng/kháng 'auk'. See võrdlus on kahtlane. Riimivastavus puudub, st teistel sama lõppriimi kandvatel eesti või soome tüvisõnadel (nt eesti rong, song) ei leidu kindlaid vasteid ülejäänud keeltes.

H2. mandariini hao 'hea' soome hyvä 'hea' eesti hää, hea, hüva - kehtiv etümoloogia, siin täiendatud sisuga

Hermanni sõna ,hao" hiina etümoloogia on tegelikult【好】： mandariini hăo 'hea', hào 'meeldima'; kantoni hou2 'hea', hou3 'meeldima'; minnani hó 'hea', hònn 'meeldima'. See võrdlus on kehtiv. Gao (2005: 85) on seda samuti võrrelnud. See etümoloogia leidub ka teistes uurali keeltes: põhjasaami savvo- 'paranema, armistuma (haava kohta)'; ersa čiv 'hea, korralik, auväärne'; mokša čiva 'hea, korralik, auväärne'; mäemari šu 'tervis; terve' (2001-SSA-1: 201, 2012-EES: 86).

Selle etümoloogia hiina vastete lõppriim ei ole otseses kooskõlas läänemeresoome, vaid põhjasaami lõppriimiga. See lõppriim kordub teises etümoloogias, st see on riimivastavuses, vt tabel 1.

Tabel 1. Riimivastavus /ao/ /ou/ /o/ /üva/ /avv/ hiina-uurali keeltes

\begin{tabular}{|c|c|c|c|c|c|c|c|}
\hline & mandariini & kantoni & minnani & eesti & soome & põhjasaami & ungari \\
\hline \multirow{2}{*}{ 【好】 } & hăo & hоu3 & hó & hüva & hyvä & sâvvo- & -- \\
\hline & 'hea' & 'hea' & 'hea' & 'hea' & 'hea' & 'paranema' & \\
\hline \multirow[b]{2}{*}{ 【滔】 } & tāo & toul & tho & süva & syvä & davvi & -- \\
\hline & ‘süva [vesi]' & 'süva [vesi]' & 'süva [vesi]' & 'süva' & 'süva' & $\begin{array}{l}\text { 'põhja } \\
\text { (ilmakaar)' }\end{array}$ & \\
\hline
\end{tabular}

5 Kummutus: Koivulehto (1977) väide, mille kohaselt see läänemeresoome tüvi (vaste soome syvä 'süva') sai olla vana laensõna „alggermaani keelest *deupa-“ (vaste nt gooti duips 'sügav', saksa tief 'sügav'), on vastuvõetamatu, sest nende hääldused ei ole kooskõlas. Tema oletatud muutus ,tyvä $<*$ tiwä $<*$ tiwp $\ddot{a}<*$ deupa-“ on liiga kunstlik ega kordu mõnes teises etümoloogias. 
Tabelis 1 olev teine etümoloogia (vaste eesti süva) sisaldabki mitteotsest sõnaalgulist vastavust, mis leidub teises etümoloogias, vt tabel 2.

Tabel 2. Sõnaalguline vastavus $/ \mathrm{t}^{\mathrm{h}} / \sim / \mathrm{s} /$ hiina-uurali keeltes

\begin{tabular}{|c|c|c|c|c|c|c|c|}
\hline & mandariini & kantoni & minnani & eesti & soome & põhjasaami & ungari \\
\hline \multirow{2}{*}{ 【滔】 } & tāo & toul & tho & süva & syvä & davvi & -- \\
\hline & 'süva [vesi]' & 'süva [vesi]' & 'süva [vesi]' & 'süva' & 'süva' & 'põhja (ilmakaar)' & \\
\hline \multirow{2}{*}{ 【匋】 } & táo & tou4 & tô & savi & savi,e & -- & -- \\
\hline & 'savi-' & 'savi-' & 'savi-' & 'savi' & 'savi' & & \\
\hline
\end{tabular}

Tänapäeva uralistika üldine väide, mille kohaselt /h-/ ei ole originaalne (/h-/ ei eksisteeri alguurali keele rekonstruktsioonis, 1988-UEW: IX), on vastuvõetamatu. Häälik /h-/ sai olla originaalne ja võib vastata regulaarselt hiina keele hälikule /h-/, vt järgmised näited tabelis 3 .

Tabel 3. Sõnaalguline vastavus $/ \mathrm{h} / \sim / \mathrm{h} /$ hiina-uurali keeltes

\begin{tabular}{|c|c|c|c|c|c|c|}
\hline & mandariini & kantoni & minnani & eesti & soome & ungari \\
\hline \multirow{2}{*}{ 【好】 } & hăo & hou3 & hó & hüva & hyvä & -- \\
\hline & 'hea' & 'hea' & 'hea' & 'hea' & 'hea' & \\
\hline \multirow{2}{*}{ 【校】 } & xiào & haau6 & hāu & halgU & halko & -- \\
\hline & 'kooritud puu' & 'kooritud puu' & 'kooritud puu' & 'halg' & 'halg' & \\
\hline \multirow{2}{*}{ 【唕】 } & háo & hou4 & hô & hauku- & hauku- & -- \\
\hline & 'haukuma' & 'haukuma' & 'haukuma' & 'haukuma' & 'haukuma' & \\
\hline \multirow{2}{*}{ 【怙】 } & $h u ̀ ~$ & wu6 & hōo & hoole & huoli,e & -- \\
\hline & 'toetuma' & 'toetuma' & 'toetuma' & ‘hool' & 'hool' & \\
\hline \multirow{2}{*}{ 【毀】 } & huॅ̆ & wai2 & hui & hukku- & hukku- & -- \\
\hline & 'hukkuma' & 'hukkuma' & 'hukkuma' & 'hukkuma' & 'hukkuma' & \\
\hline \multirow{2}{*}{ 【渾】 } & hún & wan4 & hûn & hullU & hullu & -- \\
\hline & 'sogane; hull' & 'sogane; hull' & 'sogane; hull' & 'hull' & 'hull' & \\
\hline
\end{tabular}

Mandariini keeles eesvokaali /i/ või /y/ ees olev/h/ ([x]) on muutunud sisihäälikuks /6/. Kantoni keeles poolvokaali /w/ ees olev /h/ ([h]) on ära kadunud. Kui /h/ on originaalne, on sellele loomulik muutuda sisihäälikuks või ära kaduda, samamoodi oleks juhtunud uurali keeltes ja eesti murretes. Kui / $\mathrm{h} /$-d algselt ei olnud, on imelik selleks muutuda või seda lisada. 


\section{H3. mandariini tao 'tee' $\sim$ soome tie 'tee' $\sim$ eesti tee - kehtetu etümoloogia, siin parandatud vastega}

Hermanni sõna ,tao" hiina etümoloogia on tegelikult【道】: mandariini dào 'tee'; kantoni dou3 'tee'; minnani tō 'tee'. See võrdlus on kehtetu. Nende lõppriimid ei ole kooskõlas. Seda tüve on Gao (2005: 79) võrrelnud teise hiina vastega【地】: mandariini dì 'maa'; kantoni dei6 'maa'; minnani tē/tè 'maa'. See etümoloogia leidub ka komi keeles: tuj 'tee' (2001-SSA-3: 288-289; 2012-EES: 520). Kuigi selles võrdluses on väga sarnased hääldused ja tähendused, ei ole see väga kindel, sest selle etümoloogia kõrvale ei leidu riimivastavust.

H4. mandariini niu 'tüdruk' ungari nö [nö] 'naisisik', né soome neito, neiti 'neid', nainen 'naine' eesti neid, neiu, neidi, naene [naine] - kehtiv etümoloogia, siin täiendatud sisuga

Hermanni sõna „niu“ on tegelikult põhjahiina murdesõna $n i \bar{u}$ 【妞】, millel ei ole selget hiina etümoloogiat. Ma arvan, et see murdesõna saab olla tuletis hiina etümoloogiast【女】: mandariini n nü 'naisisik'; kantoni neoi5 'naisisik'; minnani lú/lit6 'naisisik'. Seda hiina etümoloogiat on Gao (2005: 46) võrrelnud uurali tüvega, mille vasted on eesti nai- 'naima'; soome nai-7 'naima; seksima'; põhjasaami náite'naima'; njinnelas/njingálas 'emasloom'; ersa ńi 'abielunaine'; mansi $n \bar{e}$ 'naisisik; abielunaine', $n \bar{a} j$ 'daam; jumalanna'; handi niך 'naisisik; abielunaine', näj 'daam; jumalanna'; ungari nö 'naisisik'; neenetsi ne 'naisisik; abielunaine'; eenetsi ne 'naisisik; abielunaine'; nganassaani $n i$ 'naisisik'; sölkupi ne 'naisisik; abielunaine'; kamassi nē/ne 'naisisik; abielunaine' (2001-SSA-2: 202 [,,ainult läänemeresoome mansi handi; läänemeresoome > saami“], 2012-EES: 306 [,,läänemeresoome ? ülejäänud"]).

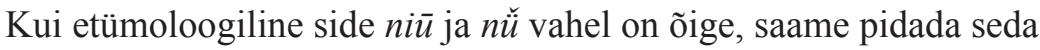
Hermanni võrdlust kehtivaks. Vahepeal peaksime kaaluma, kas eesti ja soome sõnad neid, neiu, neito, neiti ongi tuletised samast etümoloogiast.

Võrdlus mandariini $n \check{u} \sim$ eesti nai- jne vahel on väga kindel, sest see on riimivastavuses, vt tabel 4.

\footnotetext{
Minnani keeles on sõnaalguline /n/ enamasti muutunud häälikuks /1/.

7 Kummutus: Koivulehto (1988) väide, mille kohaselt see uurali tüvi (vaste soome nai'seksima') sai olla vana laensõna „algindoeuroopa keelest * gwneh $2^{-}$'naine'“ (vaste nt vanakreeka gyné 'naine'), on vastuvõetamatu, sest nende lõppriimid ei ole kooskõlas ja nende sõnaalgulised konsonandid on kunstlikult seostatud (, $\left.{ }^{*} g w n->* n-"\right)$.
} 
Tabel 4. Riimivastavus /ü/ /oei/ $\sim$ /äi/ /ö/ hiina-uurali keeltes

\begin{tabular}{|c|c|c|c|c|c|c|}
\hline & mandariini & kantoni & minnani & eesti & soome & ungari \\
\hline 【女】 & $\begin{array}{l}n \check{u} \\
\text { 'naisisik' }\end{array}$ & $\begin{array}{l}\text { neoi5 } \\
\text { 'naisisik' }\end{array}$ & $\begin{array}{l}\text { lí/lú } \\
\text { 'naisisik' }\end{array}$ & $\begin{array}{l}\text { nai- } \\
\text { 'naima' }\end{array}$ & $\begin{array}{l}\text { nai- } \\
\text { 'seksima' }\end{array}$ & $\begin{array}{l}\text { nö|neje- } \\
\text { 'naisisik' }\end{array}$ \\
\hline 【去】 & $\begin{array}{l}q \grave{u}[q \grave{u}] \\
\text { 'minema' }\end{array}$ & $\begin{array}{l}\text { heoi3 } \\
\text { 'minema' }\end{array}$ & $\begin{array}{l}k h i ̀ \\
\text { 'minema' }\end{array}$ & $\begin{array}{l}\text { käi- } \\
\text { 'käima' }\end{array}$ & $\begin{array}{l}\text { käy-|käve- } \\
\text { 'käima' }\end{array}$ & -- \\
\hline 【緒】 & $\begin{array}{l}x \grave{u}[x \grave{u}] \\
\text { 'keere' }\end{array}$ & $\begin{array}{l}\text { seoi5 } \\
\text { 'keere' }\end{array}$ & $\begin{array}{l}s \bar{u} \\
\text { 'keere' }\end{array}$ & $\begin{array}{l}\text { säie|säigme } \\
\text { 'säie' }\end{array}$ & $\begin{array}{l}\text { säielsäikee- } \\
\text { 'säie' }\end{array}$ & $\begin{array}{l}s z O ̈-\mid s z \ddot{O} v \ddot{O}- \\
\text { 'kuduma' }\end{array}$ \\
\hline
\end{tabular}

H5. mandariini $\sin$ 'süda' soome sydän 'süda' eesti süda kehtiv etümoloogia, siin täiendatud sisuga

Hermanni sõna ,sin“ hiina etümoloogia on tegelikult【心】: mandariini xīn 'süda'; kantoni saml 'süda'; minnani sim 'süda'. See võrdlus on kehtiv. Gao (2005: 63) on samuti seda võrrelnud. See etümoloogia leidub ka teiste uurali keeltes: põhjasaami čađa 'läbi, kaudu; läbinisti'; ersa śedej 'süda'; mokša śedi 'süda'; mari šüm 'süda; meel'; udmurdi śulem 'süda; sisim, põhiline; lülipuit'; komi śelem 'süda'; mansi šäm/ šim/šim/sim 'süda'; handi sěm/säm 'süda'; ungari sziv 'süda'; neenetsi śej/śej 'süda'; eenetsi seo/seijo/scj 'süda'; nganassaani sa/soa/səə 'süda'; sölkupi sīče/sìd/sīde/siče/sīća 'süda'; kamassi sī 'süda' (2002SSA-3: 228, 2012-EES: 501).

Kui uralistika arvab, et uurali sõnade lõpus olev $-m /-n$ oli algselt järgmine morfeem, ei ole see takistus, sest hiina keeles on samasugune liituv morfeem. Vaatame liitsõna võrdlust eesti ini-mene $\sim$ soome ih-minen 'ini-mene' 〜 【人物】: mandariini rén-wù 'ini-mene'; kantoni jan4-mat6 'ini-mene'; minnani jîn-bu't 'ini-mene'.

H6. mandariini kao 'kõrge' soome korkea 'kõrge' eesti kõrge kehtetu etümoloogia, siin parandatud vastega

Hermanni sõna ,kao“ hiina etümoloogia on tegelikult【高】: mandariini gāo 'kõrge'; kantoni goul 'kõrge'; minnani ko 'kõrge'. See võrdlus on kehtetu. Nende riimid ei ole kooskõlas. Gāo (2008: 153) võrdles ka neid varem nii, hiljem (Gao 2010: 209) parandas aga paremaks hiina vasteks. See parem vaste on【喬】: mandariini qiáo 'kõrge ja kõver (vananenud)'; kantoni kiu4 'kõrge ja kõver (vananenud)'; minnani kiâu 'kõrge ja kõver (vananenud)'. See etümoloogia leidub ka teistes uurali keeltes: põhjasaami goar'gâd 'kõrk'; mokša kuRka/kârka 
'süva'; mari kârâk/kurâk/kuruk 'mägi'; komi kịr 'eskarp, mägi' (1988UEW: 672 [,„äämeresoome mokša; ? mari; ? komi“"]; 2001-SSA-1: 403 [,,ainult läämeresoome; läämeresoome > saami“"], 2012-EES: 201$202[,, ? \sim$ mokša" $]$ ).

Hiina keeltes sõna 'kõrk' on samuti selle sama etümoloogia variant

【驕】: mandariini jiāo 'kõrk'; kantoni giul 'kõrk'; minnani kiau 'kõrk'. Kaks varianti on samas riimis ja ka riimivastavuses.

\section{H7. mandariini $m u$ ' 'puu' $\sim$ soome puи 'puu' $\sim$ eesti $p u u$ - kehtiv etümoloogia, siin täiendatud sisuga}

Hermanni sõna , $m u$ '“ hiina etümoloogia on【木】: mandariini mù 'puit; puu (vananenud)'; kantoni muk6 'puit; puu (vananenud)'; minnani bók/bàk 'puu; puit'. See võrdlus on kehtiv. Gao (2005: 50) on samuti seda võrrelnud. See etümoloogia leidub ka teiste uurali keeltes: mari $p u$ 'puu; puit'; udmurdi $p u$ 'puu; puit'; komi $p u$ 'puu'; mansi -pā/-pə 'puu'; ungari $f a$ 'puu; puit'; neenetsi $p \bar{a}$ 'puu; puit'; eenetsi fe/fǟ/p $\bar{a}$ 'puu'; nganassaani $f \bar{a}$ 'puu; puit'; sölkupi $p \bar{o}$ 'puu; puit'; kamassi pa 'puu; mets' (2001-SSA-2: 443-444, 2012-EES: 396-397). ${ }^{8}$

Mandariini sõnaalguline $/ \mathrm{m} /$ vastab läänemeresoome sõnaalgulisele /p/-le harva, see kordub teistes etümoloogiates, vt tabel 5.

Tabel 5. Sõnaalguline vastavus $/ \mathrm{m} / \sim / \mathrm{b} / \sim / \mathrm{p} /$ hiina-uurali keeltes

\begin{tabular}{lllllll}
\hline & mandariini & kantoni & minnani & eesti & soome & ungari \\
\hline \multirow{2}{*}{ 【木】 } & mù & 'puk6 & bók/bàk & puu & puu & $f a$ \\
& 'puit; puu' & 'puit; puu' & $\begin{array}{l}\text { 'puu; puit' } \\
\text { 'puu; puit' }\end{array}$ & $\begin{array}{l}\text { 'puu; puit' } \\
\text { 'puu; puit' }\end{array}$ \\
\hline \multirow{2}{*}{ 【冥】 } & $\begin{array}{l}\text { míng } \\
\text { 'pime' }\end{array}$ & $\begin{array}{l}\text { ming4 } \\
\text { 'pime' }\end{array}$ & $\begin{array}{l}\text { bîng } \\
\text { 'pime' }\end{array}$ & $\begin{array}{l}\text { pime } \\
\text { 'pime' }\end{array}$ & $\begin{array}{l}\text { pimeäa } \\
\text { 'pime' }\end{array}$ & -- \\
\hline \multirow{2}{*}{ 【面】 } & miàn9 & min6 & bin/biān & pindA & pinta ${ }^{10}$ & -- \\
& 'pind; nägu' & 'pind; nägu' & 'pind; nägu' & 'pind' & 'pind' & \\
\hline
\end{tabular}

8 Kummutus: Koivulehto (1991) väide, mille kohaselt see uurali tüvi (vaste soome puи 'puu') sai olla vana laensõna ,algindoeuroopa keelest *bhuH- 'puu'“ (vaste nt saksa Baum 'puu'), on vastuvõetamatu, sest nende lõppriimid ei ole kooskõlas.

9 Ka liitsõnades: eesti pindala; soome pinta-ala 'pindala'; hiina【面積】: mandariini

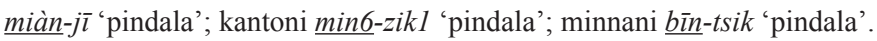

10 Kummutus: Koivulehto (1981) väide, mille kohaselt see läänemeresoome tüvi (vaste soome pinta 'pind') sai olla laensõna ,alggermaani keelest *spinda-“ (vaste nt vanainglise spind 'pekk, rasv', alamsaksa spint 'maltspuit'), on vastuvõetamatu, sest nende tähendused on kunstlikult seostatud ('pekk, rasv, maltspuit $\sim$ pind'). 


\section{H8. mandariini $t$ ' $a$ 'tema' $\sim$ eesti $t a$ - kehtiv etümoloogia, siin täiendatud sisuga}

Hermanni sõna , t' $a$ “ hiina etümoloogia on tegelikult【他】: mandariini $t \bar{a}$ 'tema'; kantoni taal 'muu'; minnani thann 'muu'. See võrdlus on kehtiv. Gao (2005: 40) on samuti seda võrrelnud. See etümoloogia leidub ka teiste uurali keeltes: soome tämä 'see'; põhjasaami diet 'see';

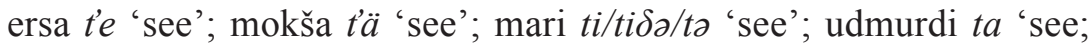
tema'; komi ta/taje 'tema'; mansi ti/tii/tit/tit/tit 'see'; handi tim/temi/ támi/tä 'see'; ungari tétova 'siia-sinna'; neenetsi tam? 'see'; tikī 'too'; eenetsi tike 'too'; nganassaani temenay 'nüüd'; sölkupi $t \bar{l}$ 'nüüd, kohe'; kamassi tije 'nüüd, kohe' (2001-SSA-3: 355, 2012-EES: 523).

Minnani vaste tõeline hääldus on [thã:] - nasaliseeritud vokaaliga. See vastab nasaalile $-m$ - uurali keeltes. Kuigi selles võrdluses on sarnased hääldused ja tähendused, ei ole see väga kindel, sest sel ei leidu riimivastavust.

Hermann (1895: 180) järeldas töö lõpus: „Die chinesische Sprache ist mit den ugro-altaischen Sprachen verwandt, also auch mit dem Finnisch-Estnischen“ [,,hiina keel on ugro-altai keeltega suguluses nagu ka soome-eesti keelega"]. Tema töö on peamiselt ainult mandariinihiina, eesti ja soome keele võrdlemine, väga väheste tõenditega teistest uurali ja altai keeltest. Ta tegi kaugeleulatuvaid järeldusi hiina-uuralialtai keelte kohta, sest uurali-altai keelesuguluse hüpotees oli tema ajal valdav. Õnneks ei olnud hiina-tiibeti keelesuguluse hüpotees tema ajal valdav. Muidu ta oleks leidnud, et hiina ja uurali keeled on seotud, aga kuna tiibeti-birma ja uurali keeled ei ole sarnased, ajasid kaks hüpoteesi teda segadusse. Tänapäeval ei ole uurali-altai ega ka hiina-tiibeti hüpotees enam valdavad (hiina-tiibeti hüpoteesi kummutamise kohta vt Miller 1974, Beckwith 2002, 2006, 2008, Guō 2010: 21, Zhāng 2012, Gao 2014a), hiina ja uurali keelte otse võrdlemine annabki rohkem häid tulemusi, nagu käesolevas artiklis näha. Kuigi Hermann (1896) on hiljem järeldanud isegi uurali ja sumeri keelesugulust, ei hakka ma seda hüpoteesi käesolevas artiklis hindama. Teadus peab olema objektiivne, peame hindama iga etümoloogilist võrdlust eraldi nagu selles artiklis. Isegi kui Hermanni keelevõrdluse üldine suund oleks hiljem väär, saaksid mõned tema detailsed etümoloogilised võrdlused ikka õiged olla. 


\section{Lõpetus}

Selles töös olen üle vaadanud Karl August Hermanni 1895. aastal ilmunud artikli, milles ta võrdles mandariinihiina keelt uurali keeltega, eriti eesti ja soome keelega, ning järeldas, et need keeled on omavahel suguluses. Hermanni toodud tõendid fonoloogia, morfoloogia ja süntaksi alal on suuresti kehtivad. Hermanni leitud sõnastuste ehk mõistete sarnasused on originaalsed. Minu hinnangul on Hermanni töös välja toodud kaheksast etümoloogilisest võrdlusest viis kehtivad, üks kahtlane, kaks kehtetud. Olen täiendanud kehtivaid võrdlusi ja parandanud kehtetuid võrdlusi. Nende etümoloogiliste võrdluste tõestamiseks olen välja toonud veel 12 etümoloogilist võrdlust, mille loovad kas sõnaalguline või riimivastavus. Tulemusena on esitatud kokku 19 hiina-uurali etümoloogiat.

Ma peaksin Hermannile kiitust avaldama. Ma ei teadnud, et Hermann võrdles hiina keelt uurali keeltega, eriti eesti ja soome keelega. Kuigi ta ei võrrelnud teisi hiina keeli peale mandariini keele, on mõned tema leiud (5/8) kehtivad. Tema töö paljastas, et tema ajal oli hiina-uurali keelesuguluse üle palju arutletud. Jingyi Gao ega Karl August Hermann ei ole esimesed uurijad, kes võrdlesid neid keeli ja järeldasid nende keelesugulust ${ }^{11}$. Jingyi Gao on aga esimene, kes tõestab hiina-uurali keelesugulust riimivastavuste ja sõnaalguliste vastavustega. Siiski oli Karl August Hermanni töö selles suunas väga oluline. Ta oli ilmselt esimene eestlane, kes uuris ja pooldas hiina-uurali keelesugulust suure lootusega.

\section{Aadress:}

Gao, Jingyi 高晶一

School of European Studies

Beijing International Studies University

Dingfuzhuangnanli 1, Chaoyang, Beijing

CN-100024, China

E-post: gao.jingyi@bisu.edu.cn; jingyi.gao@eki.ee; jingyi.gao@ut.ee

11 Seni teada kirjas kõige vanem hiina-uurali keelevõrdlus ilmus 1770. a. (Sajnovics 1770: 46-51). János Sajnovics avaldas selle paater Helli kirjast. Paater Maximilian Hell võrdles ainult mandariini keelt ungari keelega ja sai minu hinnangul kaks õiget võrdlust seitsmest võrdlusest. 


\section{Kirjandus}

1988-UEW = Károly Rédei (1988) Uralisches etymologisches Wörterbuch (Band I-III); (1991) (Band III Register). Budapest: Akadémiai Kiadó; Wiesbaden: Harrassowitz Verlag

2001-SSA = Erkki Itkonen ja Ulla-Maija Kulonen (2001) Suomen sanojen alkuperä: etymologinen sanakirja (1/2/3) (2. painos). Helsinki: Suomalaisen Kirjallisuuden Seura; Kotimaisten Kielten Tutkimuskeskus.

2003-FYZF = Běi-jīng dà-xué Zhōng-guó yǔ-yán wén-xué xì yǔ-yán-xué jiào-yán-shí (biān) (2003) Hàn-yŭ fāng-yīn zì-huì (Dì-èr-băn chóng-pái-běn). Beijing: Language $\&$ Culture Press. ${ }^{12}$

2012-EES = Iris Metsmägi, Meeli Sedrik ja Sven-Erik Soosaar (2012) Eesti etümoloogiasõnaraamat. Tallinn: Eesti Keele Sihtasutus.

Beckwith, Christopher I. (2002) „The Sino-Tibetan problem“. In Christopher I. Beckwith, ed. Medieval Tibeto-Burman Languages, 113-158. Leiden et al.: Brill.

Beckwith, Christopher I. (2006) „Old Tibetan and the dialects and periodization of Old Chinese“. In Christopher I. Beckwith, ed. Medieval Tibeto-Burman Languages II, 179-200. Leiden et al.: Brill.

Beckwith, Christopher I. (2008) „Old Chinese loans in Tibetan and the non-uniqueness of 'Sino-Tibetan'". In Christopher I. Beckwith, ed. Medieval Tibeto-Burman Languages III, 161-201. Leiden et al.: Brill.

Féng, Zhēng (2008) „Píng Gāo Jīng-ȳ̄ suǒ-zhù hàn-sòng (wū-lā-ěr-yǔ-xì-yǔ-yán) yǔ-xì xù-lùn“. Hàn-zì wén-huà 2008, 1, 57-59.13

Gao, JingYi (2005) Comparison of Swadesh 100 Words in Finnic, Hungarian, Sinic and Tibetan. Tallinn: Estonian Language Foundation.

Gāo, Jīng-ȳ̄ (2008) Hàn-yǔ yǔ Běi-ōu yǔ-yán. Beijing: China Social Sciences Press. ${ }^{14}$

Gao, Jingyi (2010) Introduction to Sino-Finnic Etymological Studies. Tartu.

Gāo, Jīng-ȳ̄ (2013) „Cóng Shěn-yáng huà dān-zì shuāng-yīn-jié bái-dú kàn qí sè-wěiyīn de yí-cún“. Yǔ-yán yán-jiū 33, 4, 50-52. ${ }^{15}$

Gao, Jingyi (2014a) „Rhyme correspondences between Sinitic and Uralic languages: on the example of the Finnish -ala and -aja rhymes“. Linguistica Uralica 50, 2, 94-108. https://doi.org/10.3176/lu.2014.2.02

Gāo, Jīng-yī (2014b) „Dān-zì shuāng-yīn-jié gǔ-yīn yí-chún jí-kăo“. Nán-kāi yǔ-yán xué-kān 2014, 1, 28-39. ${ }^{16}$

12 北京大学中国语言文学系语言学教研室编 (2003) 汉语方音字汇 (第二版重排本). 北京: 语文出版社.

13 冯蒸 (2008), 评高晶一所著汉宋(乌拉尔语系语言)语系绪论“. 汉字文化, 2008, 1, $57-59$.

14 高晶一 (2008) 汉语与北欧语言. 北京: 中国社会科学出版社.

15 高晶一 (2013) „从沈阳话单字双音节白读看其塞尾音的遗存“. 语言研究，33，4, $50-52$.

16 高晶一 (2014b) ,单字双音节古音遗存集考“. 南开语言学刊, 2014, 1, 28-39. 
Gao, Jingyi (2015a) „Keelesugulus riimivastavuse näitel: Hiina ja uurali keelevõrdluse uusimaid leide“. Sirp: Eesti Kultuurileht 10 (13.03.2015), 4.

Gao, Jingyi (2015b) „Hiina ja uurali keelte ühisest päritolust“. Ópetajate Leht 2015, 3 (30.01.2015), 20.

Gao, Jingyi (2019) „Veel hiina ja uurali keelte ühiseid etümoloogiaid riimivastavuse näitel“. Idakiri: Eesti Akadeemilise Orientaalseltsi aastaraamat 2018, 71-80.

Guō, Xī-liáng (2010) Hàn-zì gǔ-yīn shǒu-cè. Beijing: The Commercial Press. ${ }^{17}$

Hermann, Karl August (1895) „Ueber die Verwandschaft des Chinesischen mit den ugrischen Sprachen und insbesondere, mit dem Finnisch-Estnischen“. Sitzungsberichte der Gelehrten Estnischen Gesellschaft 1894, 167-180.

Hermann, Karl August (1896) „Sumeri akkadlased“. Postimees 1896, 140 (29.06.1896), 1.

Hermann, Karl August (2019) „Hiina keele sugulusest ugri keelte ja eriti soome-eesti keelega (1895)“. Tõlkinud Urmas Sutrop. Eesti ja soome-ugri keeleteaduse ajakiri 10, 2, 59-67. https://doi.org/10.12697/jeful.2019.10.2.04

Kaplinski, Jaan (2014) „Veel mõni mõtteke etümoloogiasõnaraamatust ja etümoloogiatest". Keel ja Kirjandus 2, 239-243.

Koivulehto, Jorma (1977) „Lainasanatukimuksesta“. Kielitieteen päivät Helsingissä 11.-12. helmikuuta 1977, Esitelmien ja raporttien tiivistelmät, 22-25. Helsinki.

Koivulehto, Jorma (1981) Paikan ja joukon tulo kieleen. Virittäjä, 195-213.

Koivulehto, Jorma (1988) „Idg. Laryngale und die finnisch-ugrische Evidenz“. In Alfred Bammesberger, Hg. Die Laryngaltheorie und die Rekonstruktion des indogermanischen Laut- und Formensystems, 281-297. Heidelberg: Carl Winter.

Koivulehto, Jorma (1991) „Uralische Evidenz für die Laryngaltheorie“. Sitzungsberichte der Österreichischen Akademie der Wissenschaften, Philosophisch-historische Klasse, 566, 56-59.

Künnap, Ago (2009) „Eesti keel koos teiste läänemeresoome keeltega ja germaani keeled Hiinast vaadatuna“. Keel ja Kirjandus 2, 148-150.

Künnap, Ago (2010) „Review“. Linguistica Uralica 46, 3, 218-222.

Läänemets, Märt (2010) „Arvamus“. Maaleht 14.01.2010.

Ľ́, Yàn, Băo-jiā Lǐ (2011) „Shù tǔ-huǒ-luó-yǔ zài zhèng-míng hàn-yǔ yìn-ōu-yǔ guàn-xì zhōng de zuòyòng“. Yǔ-yán kē-xué 10, 586-592.18

Miller, Roy A. 1974. „Sino-Tibetan: Inspection of a conspectus“. Journal of the American Oriental Society 94, 2, 195-209. https://doi.org/10.2307/600891

Sajnovics, Joannis (1770) Demonstratio. idioma Ungarorum et Lapponum idem esse. Tyrnavia.

Sutrop, Urmas (2010) „Arvamus“. Maaleht 14.01.2010.

Táng, Chāo, Xiān-fú Liú, Jīng-ȳ̄ Gāo (2016) „Ài-shā-ní-yà mín-zú diăn-jí de duì-wài fān-yì hé chuán-bō jīng-yàn“. Mín-zú fān-yì 2016, 3, 67-74. ${ }^{19}$

17 郭錫良 (2010) 漢字古音手册. 北京: 商務印書館.

18 李艳, 李葆嘉 (2011) , 述吐火罗语在证明汉语一印欧语关系中的作用“. 语言科学 10, 586-592.

19 唐超, 刘先福, 高晶一 (2016), 爱沙尼亚民族典籍的对外翻译和传播经验“. 民族翻译 2016, 3, 67-74. 
Wáng, Yàn-hóng (2012) Equivalents of Ancient Chinese and Turkic Languages. (Doctoral Dissertation.) Tianjin: Nankai University. ${ }^{20}$

Zhāng, Mín-quán (2012) „Hàn-zàng tóng-yuán jiă-shuō yǔ gǔ-yīn yán-jiū zhōng de ruògān wèn-tí“. Shān-xī dà-xué xué-bào (zhé-xué-shè-huì-kē-xué băn) 2012, 9, 10-17. ${ }^{21}$

\begin{abstract}
Jingyi Gao: Karl August Hermann's Chinese-Finnish-Estonian language comparison, valid and invalid etymologies with corrections. The present study inspects Karl August Hermann's article published in 1895, in which he compared Mandarin Chinese to Uralic languages, especially to Finnish and Estonian, and concluded that these languages are related. His proofs of phonology, morphology, and syntax domains are various. His findings of conception similarities are original. The present author estimates that of Hermann's eight etymological comparisons, five are valid, one is doubtful, two are invalid. The author has amended the valid comparisons and corrected invalid comparisons. In order to verify these comparisons, further 12 etymological comparisons are given, which form onset or rhyme correspondences. As a result, a total of 19 Sino-Uralic etymologies are given.
\end{abstract}

Keywords: linguistic affinity, etymology, Chinese, Sinitic, Finnish, Estonian, Sino-Uralic, Uralic, Finno-Ugric

20 王艳红 (2012) 上古汉语突厥语对应词研究 (博士学位论文). 天津: 南开大学.

21 张民权 (2012), ,汉藏同源假说与古音研究中的若干问题“. 山西大学学报（哲学社 会科学版) 2012, 9, 10-17. 